\title{
Estimates of fibre intake and percentage of the population with intake below the dietary reference values (DRVs) in England (1991-2015)
}

In 1991, the Committee on Medical Aspects of Foods (COMA) defined dietary fibre as non-starch polysaccharides (NSP) and set the DRV as the population average intake of $18 \mathrm{~g} / \mathrm{day}^{1}$, determined using the Englyst method of analysis ${ }^{2}$. The latest publication of the Scientific Advisory Committee on Nutrition (SACN) ${ }^{3}$ broadened the definition of dietary fibre beyond NSP to broader definition of Association of Analytical Communities (AOAC) fibre, recommending the DRV to be $30 \mathrm{~g} /$ day based on AOAC method. The COMA 1991, DRV of $18 \mathrm{~g} /$ day of NSP corresponds to around $24 \mathrm{~g} /$ day of AOAC fibre ${ }^{3}$ and therefore the new DRV of fibre would represent a higher recommendation (around $22.5 \mathrm{~g}$ fibre as per the Englyst method) for the average population. The purpose of this study was to investigate variation in fibre intake of English population by age and gender, in comparison with the COMA and SACN DRVs.

Data on the core sample of the National Diet and Nutrition Survey rolling programme from 2008-2012 was reanalysed. Children aged below 16 years were excluded in consideration of their different DRVs. The data on dietary fibre was extracted from fully productive individuals (i.e. participants who completed three/four diary days), as an average daily intake based on the NSP/Englyst fibre. Inferential statistics included the analysis of variance to discover if there were any significant variations in fibre intake of males and females in relation to their age groups. The statistical significance was set at $0 \cdot 05$.

Table 1. Estimates of fibre intake (g/d), density (g/1000 kcal) and percentage population with intake less than 1991 and 2015 DRVs by gender and age of participants. In rows, means that have no superscript in common are significantly different from each other $(\mathrm{P}<0 \cdot 05)$.

\begin{tabular}{|c|c|c|c|c|c|}
\hline \multirow[t]{2}{*}{ Daily fibre intake (g/day) } & \multicolumn{5}{|c|}{ Age (years) } \\
\hline & $\overline{16-18}$ & $19-34$ & $35-49$ & $50-64$ & $65+$ \\
\hline \multicolumn{6}{|l|}{$\overline{\text { Men }}$} \\
\hline Mean & $13 \cdot 1^{\mathrm{a}}$ & $14 \cdot 3^{\mathrm{a}, \mathrm{e}}$ & $14 \cdot 9^{\mathrm{b}, \mathrm{e}}$ & $15 \cdot 4^{\mathrm{b}, \mathrm{c}}$ & $14 \cdot 9^{\mathrm{b}, \mathrm{d}, \mathrm{e}}$ \\
\hline SD & $4 \cdot 7$ & $5 \cdot 3$ & $5 \cdot 2$ & 5.4 & $5 \cdot 5$ \\
\hline Mean intake per $1000 \mathrm{kcal}$ food energy & $6 \cdot 3^{\mathrm{a}}$ & $6 \cdot 6^{\mathrm{a}}$ & $7 \cdot 2^{\mathrm{b}}$ & $7 \cdot 8^{\mathrm{c}}$ & $7 \cdot 7^{\mathrm{c}, \mathrm{d}}$ \\
\hline SD & 1.6 & $2 \cdot 0$ & $2 \cdot 2$ & $2 \cdot 9$ & $2 \cdot 5$ \\
\hline Percentage with intake less than 18 & $85 \cdot 8$ & $79 \cdot 0$ & $76 \cdot 9$ & $72 \cdot 6$ & $74 \cdot 8$ \\
\hline Percentage with intake less than 22.5 & $95 \cdot 5$ & $93 \cdot 7$ & $92 \cdot 0$ & $89 \cdot 9$ & $90 \cdot 4$ \\
\hline Number (weighted) & 83 & 441 & 469 & 378 & 305 \\
\hline \multicolumn{6}{|l|}{ Women } \\
\hline Mean & $10 \cdot 6^{\mathrm{a}}$ & $12 \cdot 0^{\mathrm{b}}$ & $12 \cdot 7^{\mathrm{b}, \mathrm{c}}$ & $13 \cdot 5^{\mathrm{d}}$ & $12 \cdot 9^{\mathrm{c}, \mathrm{d}, \mathrm{e}}$ \\
\hline SD & $3 \cdot 9$ & $4 \cdot 3$ & $4 \cdot 6$ & $4 \cdot 4$ & $4 \cdot 2$ \\
\hline Mean intake per $1000 \mathrm{kcal}$ food energy & $7 \cdot 0^{\mathrm{a}}$ & $7 \cdot 6^{\mathrm{a}}$ & $8 \cdot 2^{\mathrm{b}}$ & $8 \cdot 7^{\mathrm{c}}$ & $8 \cdot 7^{\mathrm{c}, \mathrm{d}}$ \\
\hline SD & $2 \cdot 4$ & $2 \cdot 6$ & $2 \cdot 7$ & $2 \cdot 9$ & $2 \cdot 6$ \\
\hline Percentage with intake less than 18 & $95 \cdot 3$ & $90 \cdot 3$ & $86 \cdot 4$ & $86 \cdot 2$ & $88 \cdot 4$ \\
\hline Percentage with intake less than 22.5 & $99 \cdot 6$ & $97 \cdot 7$ & $96 \cdot 1$ & $97 \cdot 3$ & $97 \cdot 7$ \\
\hline Number (weighted) & 79 & 441 & 466 & 391 & 390 \\
\hline
\end{tabular}

For all age groups, the average fibre intake is below the DRVs. The average daily fibre intake slightly increased with age for both genders until 64 years. When differences in energy intake were taken into account, the average daily fibre density (g/1000 kcal) still increased with the age of participants. Overall, less than a third of populations had an intake above the COMA DRV ${ }^{1}$. More than $90 \%$ of the population had intake below the SACN DRV ${ }^{3}$, demonstrating a challenge for future policies to meet the nutritional guidelines, particularly amongst females and younger adults. The findings should be treated with caution considering the definition of AOAC fibre used as the basis for the SACN DRV includes non-digestible oligosaccharides, resistant starch and polydextrose, going beyond NSP/Englyst variables analysed.

1. Committee on Medical Aspects of Foods: Department of Health (1991) Dietary Reference Values for Food Energy and Nutrients for the United Kingdom no. 41. London: HMSO.

2. Englyst HN, Quigley ME \& Hudson GJ (1994). Analyst 119, 1497-1509.

3. Scientific Advisory Committee on Nutrition (2015) carbohydrates and Health. London: HMSO. 